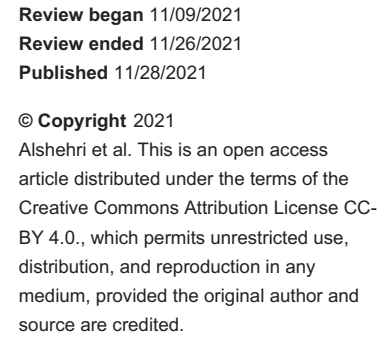

\section{Relationship Between Loneliness and Hypothyroidism}

Khalid Alshehri ${ }^{1}$, Nada E. Algethami ${ }^{2}$, Rahma A. Algethami ${ }^{2}$, Raghad H. ALAyyubi ${ }^{2}$, Ghaida H. Alotaibi ${ }^{2}$ , Jawaher S. Alotaibi ${ }^{2}$, Sheikha A. Altawairqi ${ }^{2}$

1. Family Medicine, Prince Mansour Military Hospital, Taif, SAU 2. Medicine, College of Medicine, Taif University, Taif, SAU

Corresponding author: Rahma A. Algethami ,drrahmh@gmail.com

\section{Abstract}

\section{Aim}

This study aimed to assess the relationship between loneliness and hypothyroidism in patients with hypothyroidism and to determine predictors of loneliness.

\section{Materials and methods}

A cross-sectional study was conducted on hypothyroid patients attending the endocrine clinics at Alhada Military Hospital and Prince Mansour Military Hospital, Taif, Saudi Arabia between the period of December 2020 and May 2021. Patients with more than 18 years of hypothyroidism were included and those with other thyroid diseases were excluded as well as those with other comorbidities and psychiatric disorders and those who were living alone. Data were collected using an online pre-structured questionnaire.

\section{Results}

The study included 231 hypothyroid patients with a mean age of $43.34 \pm 12.9$ years, and $90.9 \%$ were females. The majority (96.5\%) were taking levothyroxine, and $27.3 \%$ were practicing physical activity. Only $2.2 \%$ of the participants had a high degree of loneliness, whereas $47.2 \%, 34.6 \%$, and $16 \%$ had low, moderate, and moderately high degrees of loneliness, respectively.

\section{Discussion}

In this study, $2.2 \%$ of sampled hypothyroid patients had high (2.2\%) or moderately high degrees of loneliness feelings (16\%). Duration of hypothyroidism was a significant predictor for high loneliness score.

Categories: Endocrinology/Diabetes/Metabolism, Internal Medicine, Psychiatry

Keywords: thyroid hormones, saudi arabia, hypothyroid patients, loneliness predictors, $r$-ucla questionnaire

\section{Introduction}

Thyroid hormones have a major effect on all major systems, and adequate levels for optimal function are essential [1]. Pathological processes in patients with thyroid diseases commonly arise from the thyroid gland and are presented by conditions associated with deficiency of the thyroid hormones (hypothyroidism) or excessive release of hormones (hyperthyroidism) [2]. Clinical thyroid dysfunction presentation is nonspecific; therefore, the diagnosis of thyroid dysfunction is based primarily on biochemical confirmation [3]. Moreover, the most sensitive marker of thyroid dysfunction is the thyroid-stimulating hormone (TSH) level [4].

Hypothyroidism is common throughout the world. Previous studies conducted in different regions in Saudi Arabia have shown a high prevalence of hypothyroidism [3,4]. In primary hypothyroidism, the disease is in the thyroid gland itself, and TSH concentrations will be above the reference range with free T4 levels below the reference range, whereas secondary hypothyroidism is due to an anterior pituitary gland defect, resulting in decreased secretion of TSH $[1,5]$.

The relationship between thyroid hormones and TSH is influenced by many variables, including smoking, age, and thyroid peroxidase antibody status [6]. In adults, the major symptoms of hypothyroidism include cold intolerance, dry skin, and changes in voice pattern, constipation, lethargy, fatigue, and mood disorders $[7,8]$.

Loneliness is defined as emotional distress that is characterized by feelings of sadness due to the lack or absence of predictable meaningful social relationships [9]. One study performed in the United States showed that the prevalence of loneliness was $16.9 \%$. However, the risk of loneliness increases with non-married status, poor self-esteem, lower educational level, and chronic diseases [10]. In addition, for 
sociodemographic characteristics, authors have reported that loneliness is more common in women than men [11]. Loneliness has a negative impact or influence on multiple chronic diseases [12].

Furthermore, loneliness has been related to the development of chronic diseases. One study explored the associations between loneliness on metabolic biomarkers and inflammatory dysregulation. It was found that loneliness has an impact on metabolic biomarkers [13].

Social-contextual feelings, such as loneliness, affect the thyroid functioning and adaptive immune system. One study showed more fluctuation in TH secretion among people who scored low in terms of social support. This might also indicate that people who receive social support have relatively stable TH secretion [14]. In a study performed in 1999, they studied the difference between healthy and chronically ill people and found greater feelings of loneliness in ill people (in terms of their social network) [15]. Adequate social support has an association with better health and lowers loneliness among people [16].

Moreover, we cannot ignore the health impacts of loneliness among the elderly [17]. Despite the improved health consequences, the prevalence rates have persisted over several decades [18]. Only a few reviewers have focused on them despite being the highest group who experience loneliness [19]. Others have acknowledged the significant impact of loneliness on elderly people because of their normal aging process and the presence of comorbidity diseases [20]. The main effect is on their chronic diseases, which do not improve, and it becomes the main source of morbidity and mortality among the elderly [18].

To the best of our knowledge, there are very few studies that have been performed to assess the relationship between loneliness and hypothyroidism. This study aimed to determine the associations between loneliness and hypothyroidism and correlates loneliness among hypothyroid patients.

\section{Materials And Methods}

\section{Study design, setting, and time frame}

This was a cross-sectional study conducted at the endocrine clinics at Alhada Military Hospital and Prince Mansour Military Hospital, Taif, Saudi Arabia between the period of December 2020 and May 2021. The research was approved by the Research Ethics Committee of Armed Forces Hospitals, Taif region (2020-515).

\section{Study participants}

Patients who were more than 18 years of age with hypothyroidism (TSH less than $0.3500 \mathrm{mIU} / \mathrm{L}$ ) were included, and we excluded those with other thyroid diseases, other comorbidities, psychiatric disorders, and who are living alone.

\section{Data collection}

Data were collected through phone interviews using the valid online revised University of California, Los Angeles (R-UCLA) Questionnaire (Appendix Table 4). The questionnaire included the following items: personal data, such as marital status, age, gender, level of education, and socioeconomic status, and clinical data, such as duration of hypothyroidism and medication dose. Lab data were collected from medical records, including the levels of TSH, CBC, vitamin B12, and vitamin D.

\section{Clinical measurements}

To screen for loneliness, the validated R-UCLA Questionnaire was used [1]. The R-UCLA includes 20 items with each one containing a 4-point Likert scale. The maximum overall score for the 20 items is 80 , and the minimum score is 20 . Scores between 65 and 80 indicate a high degree of loneliness, 50 to 64 indicate a moderately high degree of loneliness, 35-49 indicate a moderate degree of loneliness, and 20-34 indicate a low degree of loneliness, according to Perry’s loneliness classification [21,22].

\section{Data analysis}

Data were analyzed using the SPSS program version 26 (IBM Corp., Armonk, NY). Qualitative data were expressed as numbers and percentages, and the Chi-squared test $\left(\chi^{2}\right)$ was used to test the relationship between variables. Quantitative data were presented as mean and standard deviation (mean \pm SD) and the one-way ANOVA test and Kruskal Wallis tests were used according to the data normality. Correlation analysis using the Spearman's and Pearson correlation tests was done according to the data normality. A pvalue of less than 0.05 was considered statistically significant.

\section{Results}

Table 1 shows that the mean of the participants was $43.34 \pm 12.9$ years, $90.9 \%$ were females, $84.4 \%$ were married and $40.3 \%$ had a high secondary school level of education or less. Most of them (63.6\%) had a medium socioeconomic status (SES), $1.3 \%$ were current smokers, and most of them were obese (39.8\%). The majority $(96.5 \%)$ were taking levothyroxine and $27.3 \%$ were practicing physical activity. 


\section{Cureus}

\section{Variable}

Age (mean $\pm \mathrm{SD})$

Gender

Male

Female

Marital status

Married

Single

Divorced

Widowed

Level of education

High secondary school or less

Graduated school

Bachelor's degree

Post-graduate education (Master or above)

Illiterate

\section{SES}

Low (less than 5000 SR)

Medium (5000-15,000)

High (more than 15,000 SR)

Smoking

Yes

No

Ex-smoker

Passive smoker

BMI categories

Underweight

Normal weight

Overweight

Obese

Levothyroxine use

No

Yes

Physical activity

Yes

No sedentary lifestyle

If physically active, frequency of exercise

No activity

$<150 \mathrm{~min} /$ week
168 (72.7)

No. (\%)

$43.34 \pm 12.9$

$21(9.1)$

195 (84.4)

25 (10.8)

5 (2.2)

6 (2.6)

93 (40.3)

28 (12.1)

$25(10.8)$

44 (19)

$41(17.7)$

52 (22.5)

147 (63.6)

32 (13.9)

3 (1.3)

201 (87)

7 (3)

$20(8.7)$

9 (3.9)

51 (22.1)

79 (34.2)

$92(39.8)$

8 (3.5)

223 (96.5)

63 (27.3)

168 (72.7)

35 (15.2)
210 (90.9) 


\section{Cureus}

\begin{tabular}{|l|l|}
\hline 150-300 min/week & $17(7.4)$ \\
\hline 300 min/week & $11(4.8)$ \\
\hline Variable & (Mean \pm SD) \\
Smoking duration for current smokers year & $10.7 \pm 13.57$ \\
Hypothyroidism duration/years & $8.97 \pm 5.79$ \\
\hline BMI $\left(\mathrm{kg} / \mathrm{m}^{2}\right)$ & $29.23 \pm 8.11$ \\
\hline Levothyroxine dose & $86.65 \pm 42.36$ \\
\hline TSH & $3.76 \pm 5.67$ \\
\hline T4 & $12.93 \pm 2.71$ \\
T3 & $5.33 \pm 10.31$ \\
MCHC & $129.2 \pm 138.23$ \\
\hline MCV & $83.24 \pm 8.99$ \\
MCH & $27.06 \pm 3$ \\
Hb & $97.28 \pm 53.21$ \\
Vit B12 & $323.84 \pm 148.6$ \\
Score & $28.82 \pm 24.75$ \\
\hline
\end{tabular}

TABLE 1: Distribution of the participants according to their characters, smoking, BMI, levothyroxine use, and physical activity

SES: socioeconomic status, TSH: thyroid-stimulating hormone, MCHC: mean corpuscular hemoglobin concentration, $\mathrm{MCH}$ : mean corpuscular hemoglobin, MCV: mean corpuscular volume

The mean smoking and hypothyroidism duration were $10.7 \pm 13.57$ and $8.97 \pm 5.79$ years and the mean BMI was $29.23 \pm 8.11 \mathrm{~kg} / \mathrm{m}^{2}$, respectively. The mean levels of levothyroxine dose, TSH, T4, and T3 levels were $86.65 \pm 42.36,3.76 \pm 5.67,12.93 \pm 2.71$, and $5.33 \pm 10.31$, respectively. Mean levels of MCHC, MCV, MCH, Hb, Vit B12 and Vit D were 129.2 $\pm 138.23,83.24 \pm 8.99,27.06 \pm 3,97.28 \pm 53.21,323.84 \pm 148.6$ and $28.82 \pm$ 24.75 , respectively. The mean score was $37.58 \pm 11.41$ (Table 2).

\begin{tabular}{|c|c|c|c|c|c|c|}
\hline \multirow{2}{*}{ Variable } & \multicolumn{4}{|c|}{ Degree of loneliness } & \multirow{2}{*}{$\begin{array}{l}\text { Chi-squared } \\
\text { test }\end{array}$} & \multirow{2}{*}{$\begin{array}{l}\text { P- } \\
\text { value }\end{array}$} \\
\hline & Low no. (\%) & $\begin{array}{l}\text { Moderate no. } \\
(\%)\end{array}$ & $\begin{array}{l}\text { Moderately high no. } \\
\text { (\%) }\end{array}$ & High no. (\%) & & \\
\hline \multicolumn{7}{|l|}{ Gender } \\
\hline Male & $8(38.1)$ & $6(28.6)$ & $6(28.6)$ & $1(4.8)$ & \multirow[t]{2}{*}{3.64} & \multirow[t]{2}{*}{0.303} \\
\hline Female & $101(48.1)$ & $74(35.2)$ & $31(14.8)$ & $4(1.9)$ & & \\
\hline \multicolumn{5}{|l|}{ Marital status } & \multirow{5}{*}{4.06} & \multirow{5}{*}{0.907} \\
\hline Married & $89(45.6)$ & $70(35.9)$ & $31(15.9)$ & $5(2.6)$ & & \\
\hline Single & 13 (52) & $7(28)$ & $5(20)$ & $0(0.0)$ & & \\
\hline Divorced & $4(80)$ & $1(20)$ & $0(0.0)$ & $0(0.0)$ & & \\
\hline Widowed & $3(50)$ & $2(33.3)$ & $1(16.7)$ & $0(0.0)$ & & \\
\hline \multicolumn{7}{|l|}{ Level of education } \\
\hline High secondary school or less & $40(43)$ & $33(35.5)$ & $16(17.2)$ & $4(4.3)$ & & \\
\hline
\end{tabular}




\section{Cureus}

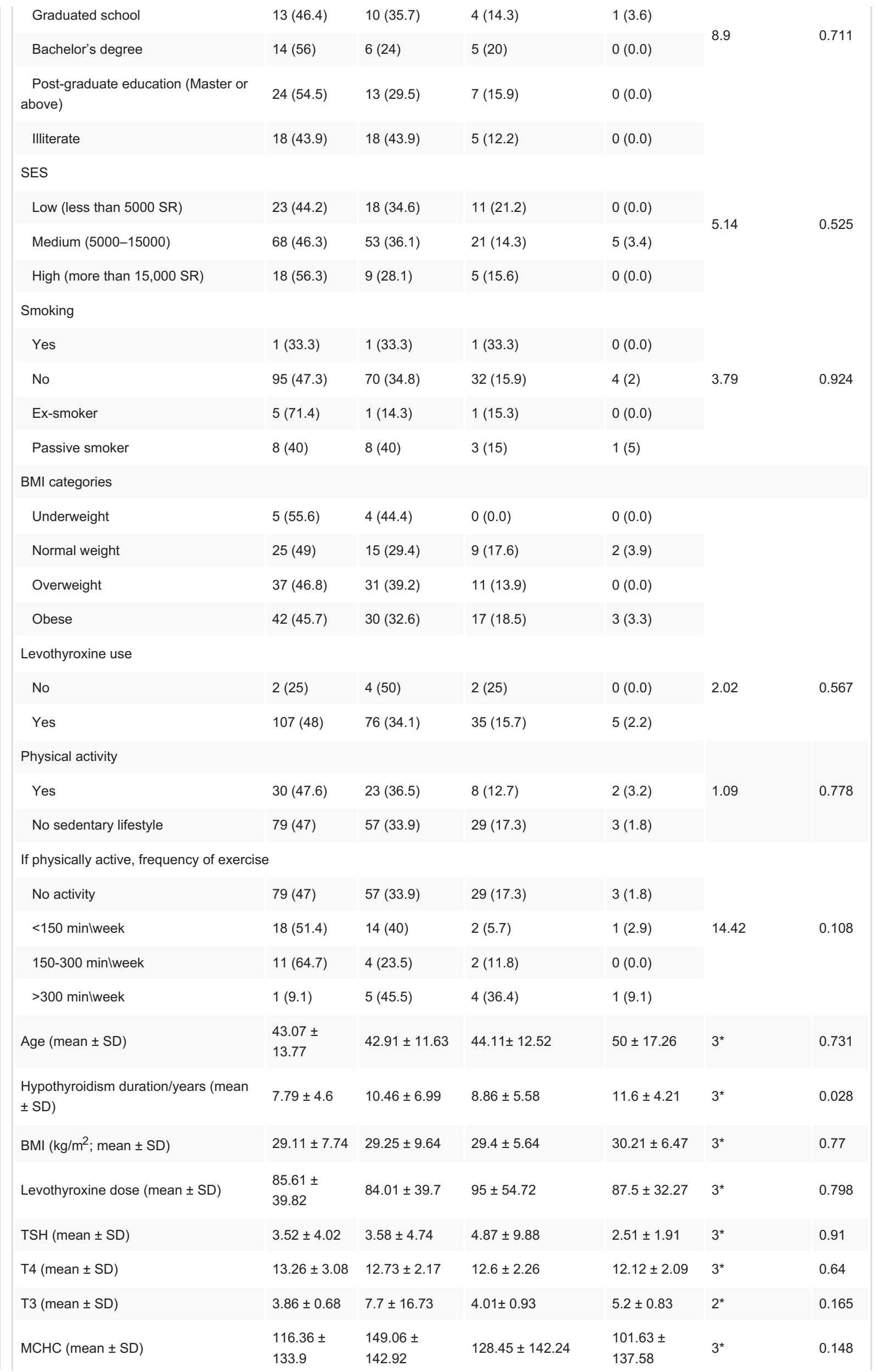




\section{Cureus}

\begin{tabular}{|c|c|c|c|c|c|c|}
\hline $\mathrm{MCV}($ mean $\pm \mathrm{SD})$ & $83.32 \pm 7.7$ & $82.25 \pm 10.96$ & $85.11 \pm 8.21$ & $84.5 \pm 5.3$ & $3^{*}$ & 0.397 \\
\hline $\mathrm{MCH}($ mean $\pm \mathrm{SD})$ & $26.96 \pm 2.84$ & $26.97 \pm 3.18$ & $27.55 \pm 3.22$ & $27.38 \pm 2.87$ & $3^{*}$ & 0.619 \\
\hline $\mathrm{Hb}($ mean $\pm \mathrm{SD})$ & $\begin{array}{l}99.38 \pm \\
52.11\end{array}$ & $92.04 \pm 55.84$ & $102.29 \pm 51.63$ & $94.5 \pm 61.02$ & $3^{*}$ & 0.782 \\
\hline Vit B12 (mean \pm SD) & $\begin{array}{l}362.44 \pm \\
97.44\end{array}$ & $\begin{array}{l}326.52 \pm \\
182.88\end{array}$ & $242.33 \pm 102.78$ & $420 \pm 120.45$ & $0.94^{* *}$ & 0.434 \\
\hline Vit $\mathrm{D}($ mean $\pm \mathrm{SD})$ & $\begin{array}{l}27.47 \pm \\
19.36\end{array}$ & $30.53 \pm 27.31$ & $24.01 \pm 19.37$ & $56.7 \pm 67.31$ & $3^{*}$ & 0.183 \\
\hline
\end{tabular}

TABLE 2: Relationship between the degree of loneliness and participants' characters, smoking, BMI, levothyroxine use, physical activity, and quantitative variables (patients's characters and clinical data)

N.B.:* Kruskal Wallis test; **one-way ANOVA test

SES: socioeconomic status, TSH: thyroid-stimulating hormone, MCHC: mean corpuscular hemoglobin concentration, $\mathrm{MCH}$ : mean corpuscular hemoglobin, MCV: mean corpuscular volume

Figure 1 illustrated that only $2.2 \%$ of the participants had a high degree of loneliness, while $47.2 \%, 34.6 \%$, and $16 \%$ had low, moderate, and moderately high degrees of loneliness, respectively.

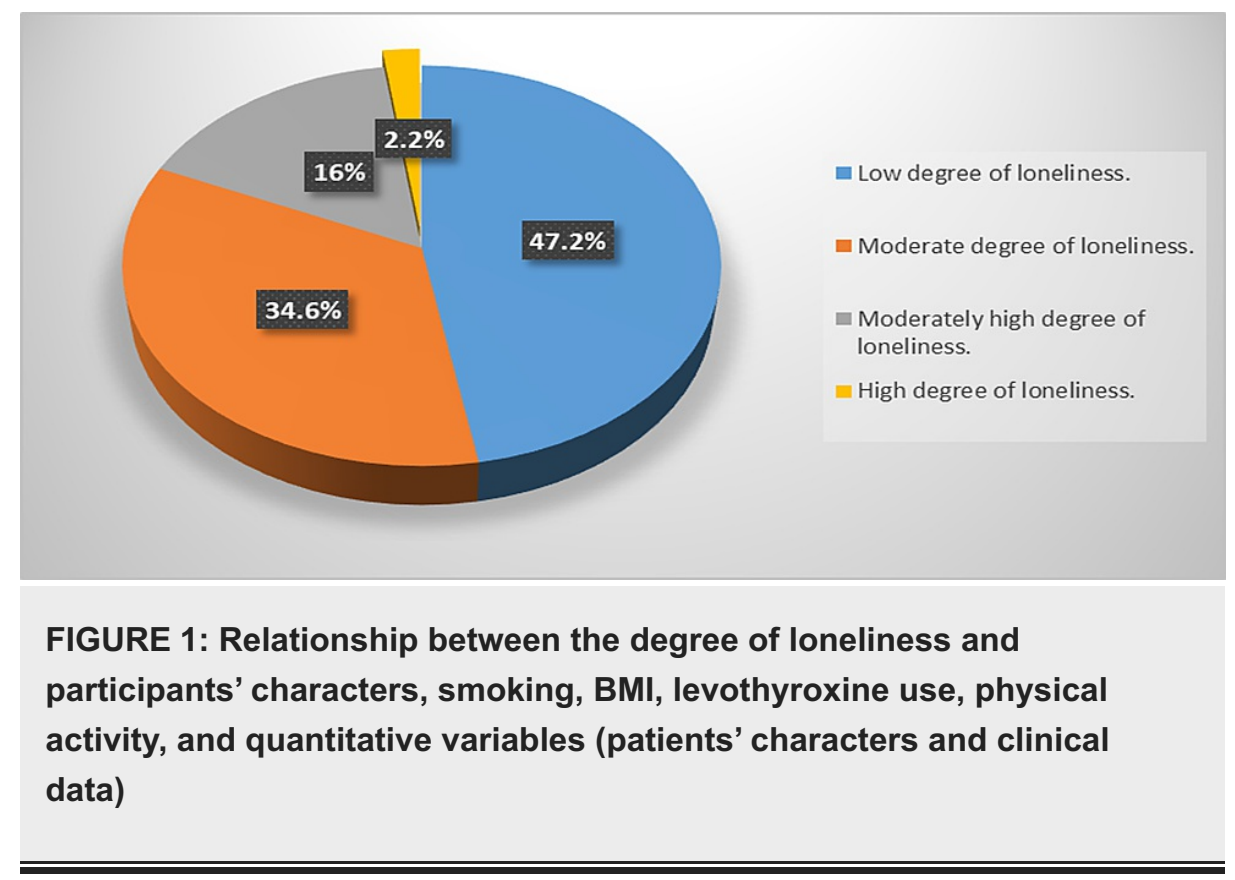

Table 3 and Appendix Table 4 demonstrated that participants who had a high degree of loneliness had a significantly higher mean hypothyroidism duration $(\mathrm{p} \leqslant 0.05)$. On the other hand, a non-significant relationship was found between the degree of loneliness and participants' gender, marital status, educational level, SES, smoking, BMI, levothyroxine use, physical activity, or clinical data other than hypothyroidism duration $(\mathrm{p} \geqslant 0.05)$. 


\section{Cureus}

\begin{tabular}{|l|l|l|}
\hline Variable & R-UCLA score & p-value \\
\hline Age (mean SD) & $r$ & 0.887 \\
\hline Smoking duration (for current smokers)/years & 0.009 & 0.231 \\
\hline BMl (kg/ $\mathrm{m}^{2}$ ) & 0.008 & 0.673 \\
Levothyroxine dose & 0.02 & 0.513 \\
\hline TSH & 0.04 & 0.987 \\
\hline T4 & -0.001 & 0.33 \\
T3 & -0.07 & 0.055 \\
MCHC & 0.24 & 0.468 \\
MCV & 0.05 & 0.28 \\
MCH & 0.07 & 0.406 \\
Hb & 0.05 & 0.947 \\
Vit B12 & 0.005 & 0.312 \\
Vit D & $-0.18^{*}$ & 0.406 \\
\hline
\end{tabular}

TABLE 3: Spearman's correlation analysis between R-UCLA scores and participants' characters and clinical data

N.B.:*Pearson correlation test

R-UCLA score: revised University of California, Los Angeles score, MCHC: mean corpuscular hemoglobin concentration, $\mathrm{MCH}$ : mean corpuscular hemoglobin, MCV: mean corpuscular volume

Table 3 shows that a non-significant positive correlation was present between the R-UCLA scores and age, smoking duration, BMI, levothyroxine dose, T3, MCHC, MCV, MCH, Hb, or Vit D levels ( $p \geqslant 0.05)$. At the same time, a non-significant negative correlation was present between the R-UCLA scores and TSH and Vit B12 levels $(p \geqslant 0.05)$.

Figure 2 shows that a significant positive correlation was found between the R-UCLA scores and hypothyroidism duration/years $(\mathrm{r}=0.12$, $\mathrm{p}$-value $=0.035)$. 


\section{Cureus}

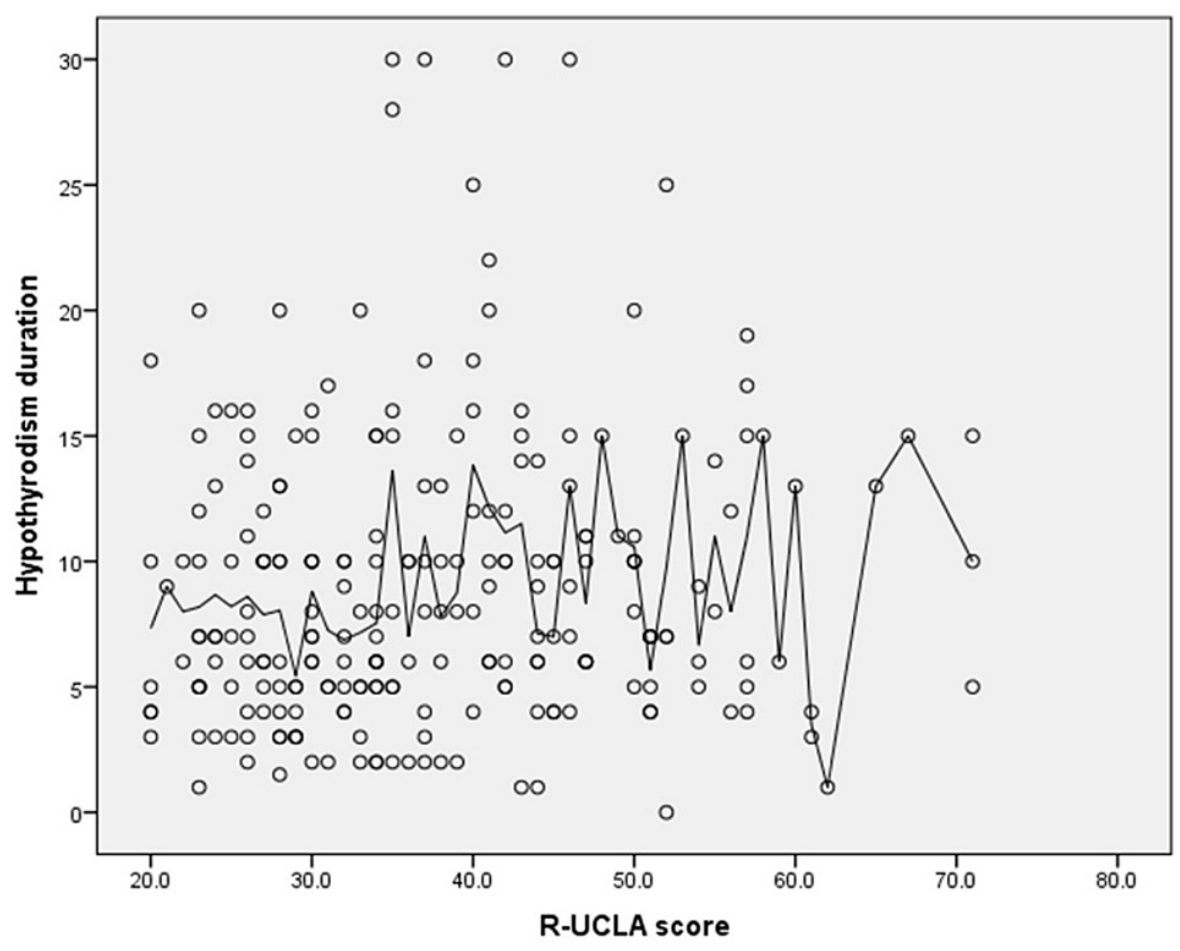

FIGURE 2: Spearman's correlation analysis between R-UCLA scores and hypothyroidism duration/years

R-UCLA scores: revised University of California, Los Angeles scores

\section{Discussion}

The current study aimed to assess the relationship between loneliness and hypothyroidism in patients with hypothyroidism and to determine predictors of loneliness level. Depression with a poor mood is one of the reported effects of clinical hypothyroidism, and that intimately reflects the mood-related symptoms of people with a depressive disorder, such as major depression, minor depression, or loneliness feelings [21]. Physicians mostly check for other related clinical features of hypothyroidism to distinguish hypothyroidism-related mood disturbance from other common sources of a persistently depressed mood [22]. There is clearly a link between thyroid problems and psycho-social disorders, according to an extensive study review published in 2012 [23].

The current study revealed that $2.2 \%$ and $16 \%$ of the studied hypothyroid patients had moderately high and high degrees of loneliness feelings, respectively. This high level of loneliness feelings had a non-significant relationship with patients' age, genders, education, SES, smoking, or practicing physical activity.

The only significant factor associated with a high level of loneliness feeling was hypothyroidism duration rather than thyroid profile (TSH, T3, and T4). This can be explained by the fact that hypothyroidism requires time to manifest in mood changes or psychological upsets and is difficult to examine with a laboratory profile. Correlation analysis showed a borderline significant relation between T3 level and the feeling of loneliness score. Hypothyroidism is one of the metabolic disorders that is associated with psychological disturbances among cases, including depression. Depressed patients lose all luxury desires and have a high tendency toward isolation, which results in loneliness preference [24,25].

Demartini et al., [24] found that $63.4 \%$ of hypothyroid patients had a diagnosis of depressive episodes with anxiety. Demartini et al., [25] reported that $63.5 \%$ of hypothyroid patients had psychological disorders. The most frequent symptoms were anxiety and somatization, cognitive impairment disturbances, psychomotor retardation, and sleep disorders, which all may end in social isolation and loneliness feelings among patients. Guimarães et al., [26] estimated that $45.7 \%$ of hypothyroid patients presented with depressive symptoms. Females with a TSH $>10 \mathrm{mUI} / \mathrm{ml}$ had a threefold likelihood of presenting depressive symptoms compared to those with normal levels of TSH. Among those with clinical hypothyroidism, the adjusted OR was 8.7. In a wider context, many studies have focused on the relationship between loneliness with social isolation and chronic diseases in general. There has been no consensus regarding the nature and significance of this relation, as some studies have confirmed this relation but other studies have failed to find any such association [27]. 


\section{Cureus}

\section{Limitations}

Our study has some limitations. First, in our opinion, an important limitation was that the use of a selfadministered questionnaire could have a recall bias. Second, the majority of our study sample was female so our study did not include undiagnosed mood disorders, menstrual cycle changes, and presence/absence of social or familial support.

\section{Conclusions}

In conclusion, the study revealed that $2.2 \%$ and $16 \%$ of the sampled hypothyroid patients had moderately high and high degrees of loneliness feelings, respectively. The only significant predictor for high loneliness score was hypothyroidism duration rather than thyroid profile or other patient-related factors.

\section{Appendices}

Questionnaire

1- Marital status:

a. Married

b. Single

c. Divorced

d. Widow

2- Age: In years

3- Gender:

a. Male

b. Female

4- Level of education:

a. None

b. High secondary school or less

c. Bachelor's degree

d. Master degree

5- Socioeconomic status

a. Low (less than 5000 SR)

b. Medium (5000-15,000)

c. High (more than 15,000 SR)

6- Smoking:

a. Yes (if yes for how long, which type)

b. No 


\section{Cureus}

c. Ex-smoker

d. Passive smoker

7- Do you live alone?

a. Yes

b. No

8- Do you have any chronic diseases?

a. No

b. Yes (diabetes)

c. Yes (hypertension)

9- Duration of hypothyroidism: in years

10-Medication use (levothyroxine)

a.yes

b.no

11- Dose of levothyroxine? (...)

12- Physical activity

a. Sedentary lifestyle

b. $<150$ minutes $\backslash$ week

c. Around 150-300 minutes \week

d. >300 minutes $\backslash$ week

13- Do you live alone?

a.Yes

b.No

14- Hight (cm)

15- Weight (kg) 


\section{Cureus}

\begin{tabular}{|c|c|c|c|c|}
\hline Statement & Never & Rarely & Sometimes & Often \\
\hline 1- I feel in tune with the people around me & 1 & 2 & 3 & 4 \\
\hline 2-I lack companionship & 1 & 2 & 3 & 4 \\
\hline 3- There is no one I can turn to & 1 & 2 & 3 & 4 \\
\hline 4- I do not feel alone & 1 & 2 & 3 & 4 \\
\hline 5-I feel part of a group of friends & 1 & 2 & 3 & 4 \\
\hline 6- I have a lot in common with the people around me & 1 & 2 & 3 & 4 \\
\hline 7-I am no longer close to anyone & 1 & 2 & 3 & 4 \\
\hline 8- My interests and ideas are not shared by those around me & 1 & 2 & 3 & 4 \\
\hline 9- I am an outgoing person & 1 & 2 & 3 & 4 \\
\hline 10- There are people I feel close to & 1 & 2 & 3 & 4 \\
\hline 11- I feel left out & 1 & 2 & 3 & 4 \\
\hline 12- My social relationships arc superficial & 1 & 2 & 3 & 4 \\
\hline 13- No one really knows me well & 1 & 2 & 3 & 4 \\
\hline 14- I feel isolated from others & 1 & 2 & 3 & 4 \\
\hline 15- I can find companionship when I want it & 1 & 2 & 3 & 4 \\
\hline 16- There are people who really understand me & 1 & 2 & 3 & 4 \\
\hline 17- I am unhappy being so withdrawn & 1 & 2 & 3 & 4 \\
\hline 18- People are around me but not with me & 1 & 2 & 3 & 4 \\
\hline 19- There are people I can talk to & 1 & 2 & 3 & 4 \\
\hline 20- There are people I can turn to & 1 & 2 & 3 & 4 \\
\hline
\end{tabular}

TABLE 4: Loneliness score

\section{Additional Information}

\section{Disclosures}

Human subjects: Consent was obtained or waived by all participants in this study. Research Ethics Committee of Armed Forces Hospitals, Taif region issued approval 2020-515. The research was approved by the Research Ethics Committee of Armed Forces Hospitals, Taif region (2020-515). Animal subjects: All authors have confirmed that this study did not involve animal subjects or tissue. Conflicts of interest: In compliance with the ICMJE uniform disclosure form, all authors declare the following: Payment/services info: All authors have declared that no financial support was received from any organization for the submitted work. Financial relationships: All authors have declared that they have no financial relationships at present or within the previous three years with any organizations that might have an interest in the submitted work. Other relationships: All authors have declared that there are no other relationships or activities that could appear to have influenced the submitted work.

\section{Acknowledgements}

The authors thank the participants of this work for their cooperation.

\section{References}

1. Leng O, Razvi S: Hypothyroidism in the older population. Thyroid Res. 2019, 12:2. 10.1186/s13044-0190063-3

2. Persani L: Clinical review: central hypothyroidism: pathogenic, diagnostic, and therapeutic challenges . J Clin Endocrinol Metab. 2012, 97:3068-78. 10.1210/jc.2012-1616

3. Taylor PN, Albrecht D, Scholz A, Gutierrez-Buey G, Lazarus JH, Dayan CM, Okosieme OE: Global epidemiology of hyperthyroidism and hypothyroidism. Nat Rev Endocrinol. 2018, 14:301-16. 
10.1038/nrendo.2018.18

4. Katznelson L, Laws ER Jr, Melmed S, Molitch ME, Murad MH, Utz A, Wass JA: Acromegaly: an endocrine society clinical practice guideline. J Clin Endocrinol Metab. 2014, 99:3933-51. 10.1210/jc.2014-2700

5. Kumar V, Abbas A, Mitchell R, Fausto N: Robbins Basic Pathology. Saunders/Elsevier, Philadelphia; 2017. https://www.amazon.com/Robbins-Basic-Pathology-Eighth-Vinay/dp/1416029737.

6. Brown SJ, Bremner AP, Hadlow NC, Feddema P, Leedman PJ, O'Leary PC, Walsh JP: The log TSH-free T4 relationship in a community-based cohort is nonlinear and is influenced by age, smoking and thyroid peroxidase antibody status. Clin Endocrinol (Oxf). 2016, 85:789-96. 10.1111/cen.13107

7. Alreshidi FS, Alreshidi NF: Knowledge of hypothyroidism associated disorders and symptoms: a Saudi community-based study. Med Sci. 2020, 24:2870-6. 10.15761/TDM.1000107

8. Rack SK, Makela EH: Hypothyroidism and depression: a therapeutic challenge. Ann Pharmacother. 2000, 34:1142-5. 10.1345/aph.10022

9. Richard A, Rohrmann S, Vandeleur CL, Schmid M, Barth J, Eichholzer M: Loneliness is adversely associated with physical and mental health and lifestyle factors: Results from a Swiss national survey. PLoS One. 2017, 12:e0181442. 10.1371/journal.pone.0181442

10. Theeke LA: Sociodemographic and health-related risks for loneliness and outcome differences by loneliness status in a sample of U.S. older adults. Res Gerontol Nurs. 2010, 3:113-25. 10.3928/19404921-20091103-99

11. De Jong Gierveld J, Van Tilburg T: The De Jong Gierveld short scales for emotional and social loneliness: tested on data from 7 countries in the UN generations and gender surveys. Eur J Ageing. 2010, 7:121-30. 10.1007/s10433-010-0144-6

12. Petitte T, Mallow J, Barnes E, Petrone A, Barr T, Theeke L: A systematic review of loneliness and common chronic physical conditions in adults. Open Psychol J. 2015, 8:113-32. 10.2174/1874350101508010113

13. Shiovitz-Ezra S, Parag O: Does loneliness 'get under the skin'? Associations of loneliness with subsequent change in inflammatory and metabolic markers. Aging Ment Health. 2019, 23:1358-66. 10.1080/13607863.2018.1488942

14. Masih J, Belschak F, Verbeke JM: Mood configurations and their relationship to immune system responses: Exploring the relationship between moods, immune system responses, thyroid hormones, and social support. PLoS One. 2019, 14:e0216232. 10.1371/journal.pone.0216232

15. Penninx BW, van Tilburg T, Kriegsman DM, Boeke AJ, Deeg DJ, van Eijk JT: Social network, social support, and loneliness in older persons with different chronic diseases. J Aging Health. 1999, 11:151-68. 10.1177/089826439901100202

16. Segrin C, Domschke T: Social support, loneliness, recuperative processes, and their direct and indirect effects on health. Health Commun. 2011, 26:221-32. 10.1080/10410236.2010.546771

17. Malcolm M, Frost H, Cowie J: Loneliness and social isolation causal association with health-related lifestyle risk in older adults: a systematic review and meta-analysis protocol. Syst Rev. 2019, 8:48. 10.1186/s13643019-0968-x

18. Victor CR, Scambler S, Bowling AN, Bond J: The prevalence of and risk factors for, loneliness in later life: a survey of older people in Great Britain. Ageing Society. 2005, 25:357-75. 10.1017/S0144686X04003332

19. Luanaigh CO, Lawlor BA: Loneliness and the health of older people. Int J Geriatr Psychiatry. 2008, 23:121321. 10.1002/gps.2054

20. Calsolaro V, Niccolai F, Pasqualetti G, et al.: Hypothyroidism in the elderly: who should be treated and how?. J Endocr Soc. 2019, 3:146-58. 10.1210/js.2018-00207

21. Russell D, Peplau LA, Cutrona CE: The revised UCLA Loneliness Scale: concurrent and discriminant validity evidence. J Pers Soc Psychol. 1980, 39:472-80. 10.1037/0022-3514.39.3.472

22. Carta MG, Hardoy MC, Boi MF, Mariotti S, Carpiniello B, Usai P: Association between panic disorder, major depressive disorder and celiac disease: a possible role of thyroid autoimmunity. J Psychosom Res. 2002, 1:789-93. 10.1016/S0022-3999(02)00328-8

23. Fukao A, Takamatsu J, Murakami Y, et al.: The relationship of psychological factors to the prognosis of hyperthyroidism in antithyroid drug-treated patients with Graves' disease. Clin Endocrinol (Oxf). 2003, 58:550-5. 10.1046/j.1365-2265.2003.01625.x

24. Demartini B, Masu A, Scarone S, Pontiroli AE, Gambini O: Prevalence of depression in patients affected by subclinical hypothyroidism. Panminerva Med. 2010, 52:277-82.

25. Demartini B, Ranieri R, Masu A, Selle V, Scarone S, Gambini O: Depressive symptoms and major depressive disorder in patients affected by subclinical hypothyroidism: a cross-sectional study. J Nerv Ment Dis. 2014, 202:603-7. 10.1097/NMD.0000000000000168

26. Guimarães JM, de Souza Lopes C, Baima J, Sichieri R: Depression symptoms and hypothyroidism in a population-based study of middle-aged Brazilian women. J Affect Disord. 2009, 117:120-3. 10.1016/j.jad.2008.12.012

27. Roca M, Mitu O, Roca IC, Mitu F: Chronic diseases - medical and social aspects . Revista Cercetare Interventie Sociala. 2015, 49:257-75. 